\title{
Integrated assessment and adaptation to climate change impacts in the Peruvian Andes
}

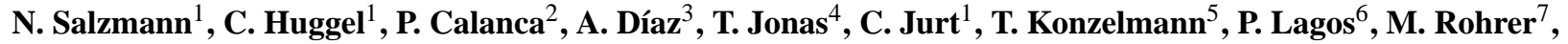 \\ W. Silverio ${ }^{8}$, and M. Zappa ${ }^{4}$ \\ ${ }^{1}$ Department of Geography, University of Zurich, Switzerland \\ ${ }^{2}$ Agroscope Reckenholz-Tänikon, Research Station ART, Zurich, Switzerland \\ ${ }^{3}$ Servicio Nacional de Meteorología e Hidrología, Senamhi, Lima, Peru \\ ${ }^{4}$ Swiss Federal Institute for Forest, Snow and Landscape Research, Birmensdorf and Davos, Switzerland \\ ${ }^{5}$ Federal Office of Meteorology and Climatology, MeteoSwiss, Zurich, Switzerland \\ ${ }^{6}$ Instituto de Geofísico, Lima, Peru \\ ${ }^{7}$ Meteodat GmbH, Zurich, Switzerland \\ ${ }^{8}$ University of Geneva, Switzerland
}

Received: 1 May 2009 - Revised: 12 June 2009 - Accepted: 17 June 2009 - Published: 13 October 2009

\begin{abstract}
The Andes as mountain regions worldwide, provide fundamental resources, not only for the local population. Due to the topographic characteristics, the potential for natural hazards is higher than elsewhere. In these areas, assessments of climate change impacts and the development of adequate adaptation strategies therefore become particular important. The data basis, however, is often scarce. Moreover, perceptions of changes and needs are often divergent between national and local levels, which make the implementation of adaptation measures a challenge. Taking the Peruvian Andes as an example, this paper aims at initiating a discussion about scientific baseline and integrative concepts needed to deal with the adverse effects of climate change in mountain regions.
\end{abstract}

\section{Introduction}

While climate change is a global problem, the impacts are felt by the human society mainly on regional to local scales. The tropical Andes are often declared as one of the most vulnerable regions to climate change worldwide (IPCC, 2007), and the countries there are already facing major challenges in coping with climate variability (Bradley et al., 2006). The

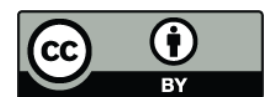

Correspondence to: N. Salzmann (nadine.salzmann@geo.uzh.ch) adverse effects of climate change are expected to affect in particular the poorest people because of their high vulnerability and low adaptive capacity. Furthermore, climate change impacts are manifold and multidimensional, and thus developing and implementing adequate adaptation measures is complex. Changes in the amount and temporal availability of water, for example, related to glacier retreat/disappearance, drought or intense precipitation have potentially negative impacts on various sectors like fresh water supply, agriculture and power production (Barnett et al., 2005; Vergara et al., 2007). Additionally, they can give rise to natural disasters like landslides (Fig. 1).

In order to provide a basis for adaptation and reduction of adverse impacts, climate change impacts assessments at the regional to local level are needed. For that purpose, data and scenarios for the relevant scales are required. The availability of climate data in remote mountain regions, however, is often very limited and scenario simulations particularly difficult. As a consequence, planning and decision-making must be made under great uncertainties. Therefore, it is an urgent need to provide a scientific baseline, methods and tools to support the development and implementation of adequate adaptation measures.

A major undertaking concerning the aforementioned issues is the recently launched Program on Climate Change Adaptation in Peru PACC (Programa de Adaptación al Cambio Climático en el Perú). PACC focuses on two Andean Regions of Peru, Cusco and Apurímac (Fig. 2a), and

Published by Copernicus Publications on behalf of the European Geosciences Union. 


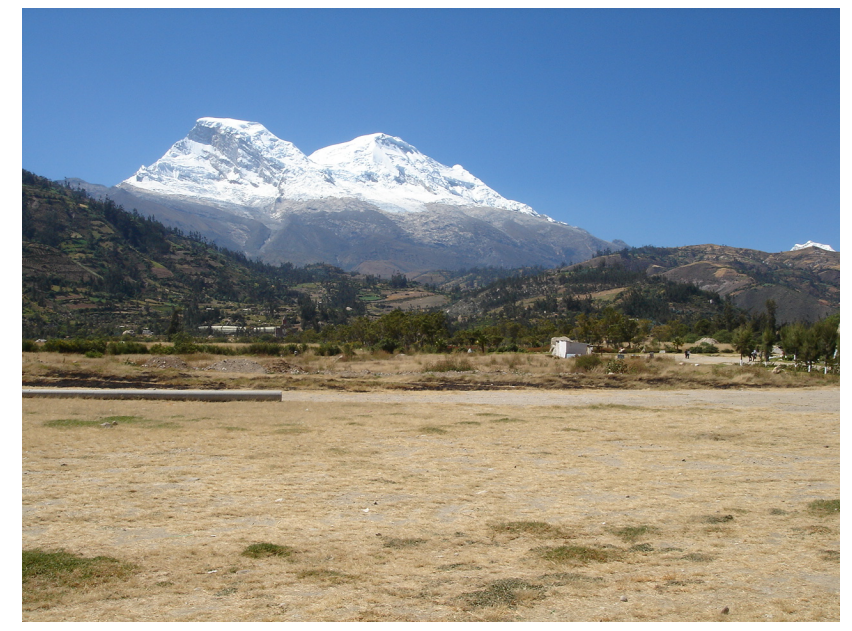

Fig. 1. The Huascarán, the highest peak in the Peruvian Andes, and its glacier represent both benefit and threat for the local population: a massive ice-rock avalanche in 1970 devastated the town of Yungay killing 20000 residents - melt water from the glaciers are an essential source of freshwater in the dry austral winter. Climate change is likely to alter both the benefit and threat (photo C. Huggel).

is a joint effort of the Peruvian and Swiss Governments (Swiss Agency for Development and Cooperation, SDC). A large number of different institutions and actors in Peru and Switzerland participate, including national, regional and local governments, NGO's, universities and research institutions. The main goal of PACC is to improve the adaptive capacities of the local population, through provision of a number of adaptation measures and stimulation of the awareness at different social and political levels.

The program includes a scientific component that aims at identifying scientific gaps and providing approaches to overcome the main weaknesses. Furthermore, the improvement of the dialogue between the scientific community, implementing agencies and political authorities is another vital aspect of PACC that is expected to increase awareness and promote adaptation.

The purpose of our article is to initiate the discussion on scientific issues and to outline some of the major needs regarding integrated climate change impacts assessments and the scientific baseline required in an Andean context.

\section{Climate trends in the Peruvian Andes}

Results from climate trend studies for South America in general agree with observed trends in other parts of the world. For instance, Vincent et al. (2005) noticed increasing/decreasing trends in the percentage of warm/cold nights for many stations across South America for the period 1960 2000. For the same time period, Haylock et al. (2006) reported a trend to generally wetter conditions for South Amer-

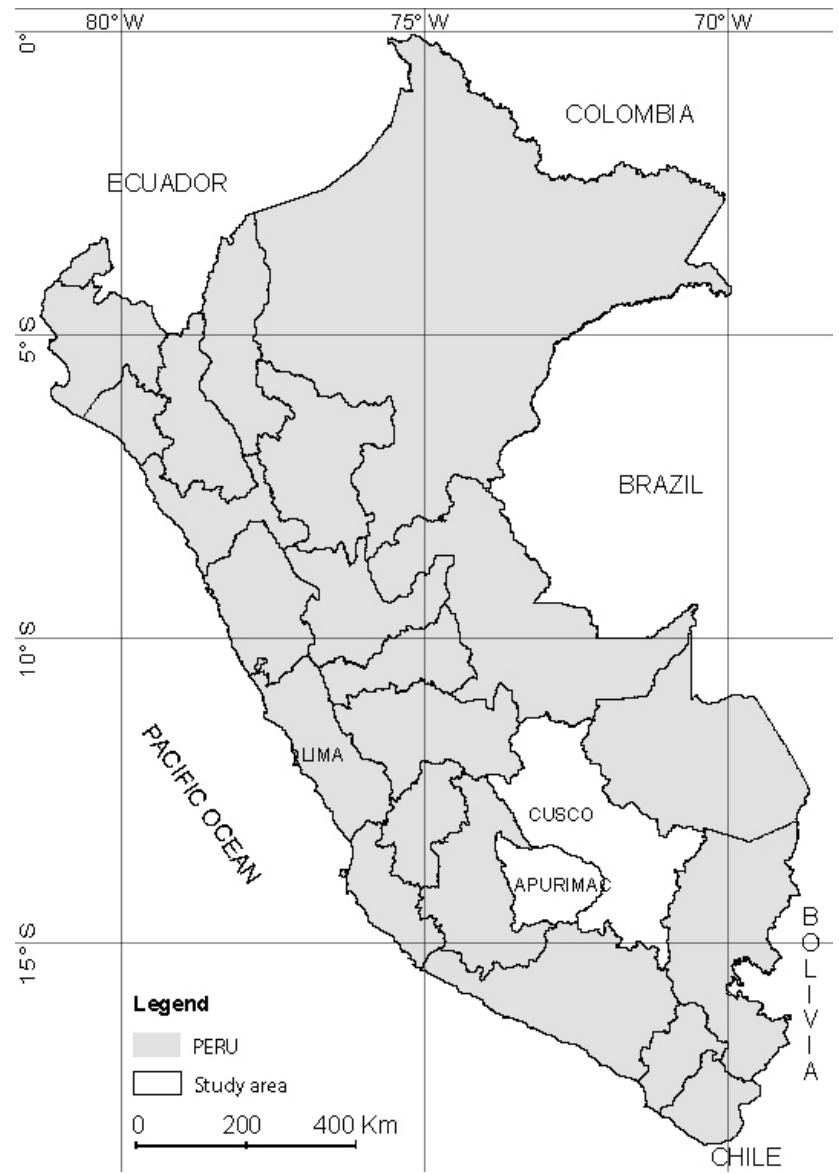

Fig. 2a. Overview map Peru. PACC's geographical focus is on the two Regions Cusco and Apurimac (high-lighted).

ica. Both studies include a good number of quality checked and homogenous long-term station data across South America. However, there is an obvious lack of data from the high altitude mountain regions in the tropical Andes, where the regional patterns not necessarily correspond with large scale trends.

Poor data coverage in the tropical Andes has been examined in more details by Vuille and Bradley (2000) and Vuille et al. (2003). Based on a number of observational datasets, including observed glacier retreat and model diagnostics from a General Circulation Model (GCM), they found significant and accelerating warming trends for the tropical Andes. The warming trend seems to be less pronounced at higher elevations. Furthermore, a distinction can be made between the east (less warming) and west (more warming) slopes of the Andean chain. Still at a higher level of resolution, differing patterns emerge for northern and southern Peru, with only weak or insignificant trends regarding the latter. In contrast to the above findings Bradley et al. (2006) report on free surface temperature projections that indicate an increased warming at higher elevation in the Andes. Note, however, that for southern Peru the availability 
and reliability of climate data is particularly weak. In summary, for the target area of PACC, no clear climate trend patterns can be detected from the mentioned datasets.

\section{Scientific data gaps in mountain regions}

A proper characterization of current trends in climatic conditions, issued from an analysis of historical data, is indispensable for the correct interpretation of climate scenarios. In developing countries, climate impacts assessments are often confronted with a poor data basis. This is true in particular with respect to mountain regions, where complex topography gives rise to heterogeneous local to microclimatic conditions and where routine measurements are considerably complicated by difficult access and maintenance of weather stations. Even though efforts to improve the observational network are on the way, data gaps remain one of the major problems faced during the analysis of historical data. Efforts undertaken for instance in the US to provide regional reanalysis and gridded data with a horizontal resolution of $32 \mathrm{~km}$ (NARR; Mesinger et al., 2006) would enable to partly overcome problems with data gaps. Nevertheless, additional initiatives towards new ways and methods of generating and providing reliable scientific data are essential for programs like the PACC

\section{Composing scientific baseline}

For the Cusco and Apurímac regions in Peru, the Peruvian meteorological office (SENAMHI) owns several longterm ( $>40$ years) and a good number of shorter-term records ( $<40$ year), and some additional time series with, however, significant data gaps (Fig. 2b). In addition, there are a few weather records available from private companies. Most stations are generally in good condition and well maintained.

Within the scope of PACC, the data go through a data quality check with different levels of sophistication. Filling temporal and spatial data gaps is another vital undertaking towards the preparation of climatological basis for further scientific studies. There are several sources of complementary data, including glacier-related proxies, satellite data and reanalyses that can be considered for gap filling and are going to be evaluated within PACC.

Glacier monitoring provides valuable indirect climate information through mass-balance data, historic glacier-length records or ice-core information (Kaser et al., 2003; Thompson et al., 2003). Another source of information are glacier outlines from satellite images now available for more than 20 years. Satellites, furthermore, are also capable to provide more direct climate data. For example, the satellite TRMM (Tropical Rainfall Measurement Mission) has been in orbit for more than ten continuous years now. TRMM Multisatellite Precipitation Analysis (TMPA) offers 3 hourly precipitation data with a horizontal resolution of $25 \mathrm{~km}$. TMPA

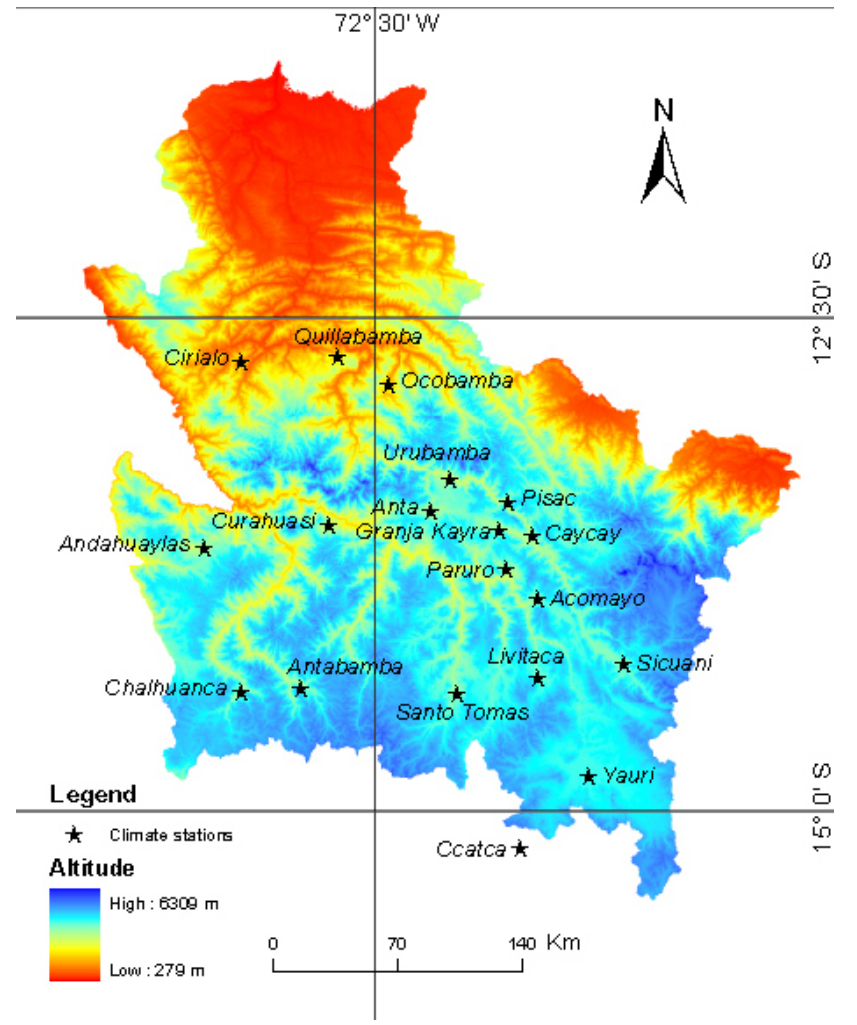

Fig. 2b. The distribution of climate stations in the Regions Cusco and Apurimac, an area with significant topography.

has shown reasonable results in applications in various regions worldwide and also in South America (e.g. Su et al., 2008). However, its effective potential and performance for the tropical Andes has yet to be evaluated. First analyses undertaken within PACC indicate that the TRMM based product TMPA shows, compared against ground observations, rather modest verification scores for short time steps and fine resolution as daily values and $25 \mathrm{~km}$ resolution in the area Cusco/Apurimac (Fig. 3).

For hydrological studies, other components of the hydrological cycle in addition to precipitation must be investigated. For the Andes, knowledge of glacier run-off is an essential piece of information. In the tropics, glacier dynamics is mainly dictated by relative humidity and radiation (Kaser and Osmaston, 2002), and these variables are therefore needed to model glacier run-off. In absence of automatic weather stations at high-elevation glacier sites, these specific variables may be derived from reanalyses (Fig. 4). Their current horizontal resolution of 100-250 km, however, requires further spatial downscaling before the data can be used. The same is true for climate scenarios from GCMs (Fig. 4) and RCMs (Salzmann et al., 2006). PACC will apply and analyse statistical and dynamical downscaling approaches in order to derive plausible information about possible ranges of future climate and thus providing critical information for the development of adaptation strategies. 


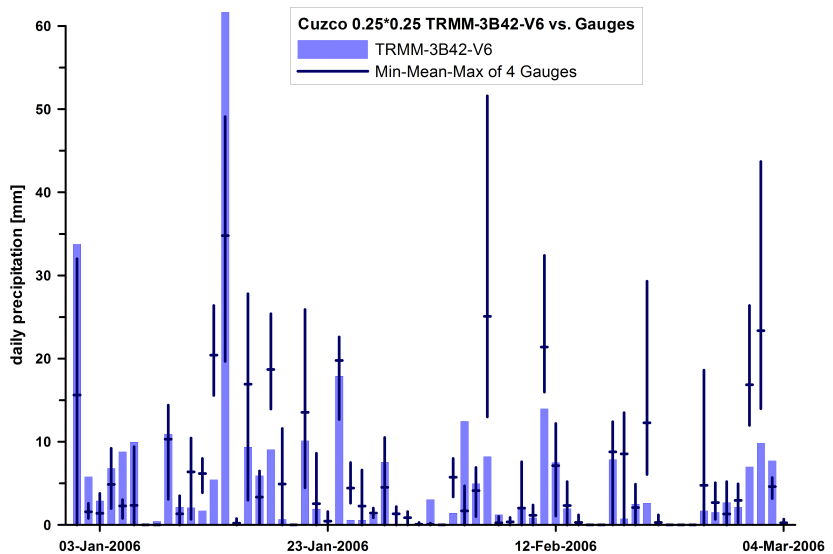

Fig. 3. Comparison of TRMM 3B42 V6 and gauge daily precipitation for Cuzco, Peru (January to March 2006). Shown are the arithmetic mean, maximum and minimum of the ground truth (4 gauges).

\section{Including the human dimension}

Climate change affects the society and their livelihoods on multiple levels (national, regional, local). Impacts are not only felt directly through droughts, cold waves or frost, but also indirectly e.g. through conservation of food, effects of natural hazards on infrastructure, and the like. Agricultural activities and tourism have to be re-thought, questions of health have to be taken differently into consideration. It is essential that adaptation measures are not only prepared on the basis of analysis of physical processes, but also with due consideration of the perceptions of ongoing changes by the local populations and its vulnerability to climate variability and change (Gilles and Valdivia, 2007). Their perceptions and everyday knowledge shaped through the natural, social, cultural, economic, political context and their historical experiences (Hewitt, 2002) are crucial for the application of adaptation measures on site and eventually improve people's livelihood. Analysis of the human dimension is an integral component of the PACC. People's perception will be assessed through different methods as semi-structured interviews at different political levels and local focus groups. Moreover, information systems on regional and local scales will be set up. The development and implementation of adaptation measures will be realized by means of participatory approaches concerning different political levels, including the community level.

\section{Improving the science-policy dialogue}

Communicating scientific results to the policy is challenging but absolutely vital for the science of climate change (e.g. Moser and Dilling, 2007). An example is the discussion in the media on the consensus on climate change in the

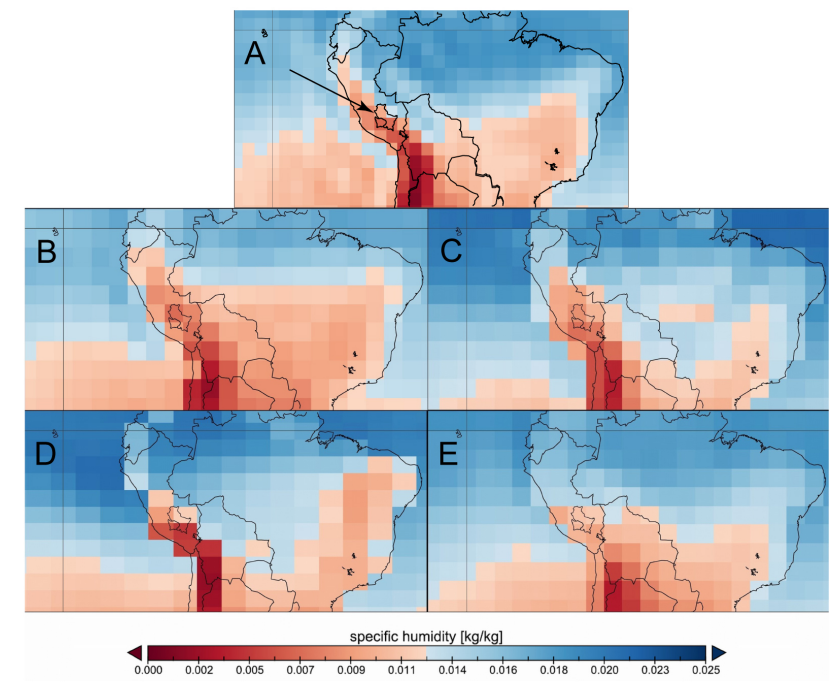

Fig. 4. As an example of climate projections, mean specific humidities are shown for June 1980-1999 based on NCEP Reanalysis (A), and for 2046-2065 for SRES-scenario A1B as modelled in the Global Circulation Models for the central part of South America: Bjerknes Center BCM2 (B), Canadian Center CGHR (C), Hadley Center CM3 (D) and Meteorological Institute of Japan MRIMRCGCM (E). These IPCC-AR4 based results do not provide sufficient detail and clarity as to whether the dry austral winters in the regions of Cusco and Apurímac (geographic limits indicated) will even be drier in future than at present (data courtesy IPCC).

Knowledge demand by
society \& politics
- Clear picture of future regional
climate
- Probability and magnitude of
impacts
- Long-term observations
- Information needed now

- Information needed now

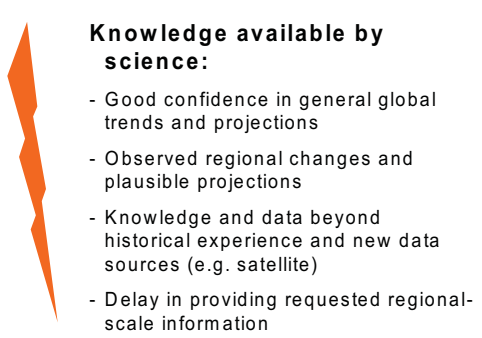

Fig. 5. The discrepancy between knowledge demand and knowledge availability.

scientific community where the existing degree of consensus is often inadequately reflected (Doran and Kendall Zimmermann, 2009). Since adaptation processes take place within institutionally rich contexts, it is crucial to integrate institutions from all political levels (from national to local) in early stages of adaptation programs. This allows building upon already existing institutional structures and responses to environmental changes (Agrawal, 2007), enhances the support and makes measures (more) sustainable. Political leaders need thereby to be informed on an adequate degree of detail to be able to take appropriate measures. A major difficulty in this context is the existence of an often wide 
discrepancy between demand for and supply of knowledge (Fig. 5). In particular programs like the PACC face the problem that decision-making must be carried out mostly under huge uncertainties (Dessai et al., 2009). Science is thereby challenged by the needs to provide answers to concrete questions, yet without fully understanding relevant aspects of climate change impacts at local or regional scale.

\section{Conclusions and perspectives}

Ideally, guidelines and tools would be available for each of the sections discussed above, in order to provide an optimal baseline for the derivation of adaptation measures. Apparently, this is not the case and in view of integrated assessments considerable efforts are still needed. The scientific community currently has to face pressing demands from the policy and decision-makers regarding climate change impacts at the local and regional scale. However, as pointed out in this paper, in mountain regions in developing countries the required scientific baseline is largely lacking, incomplete and/or associated with considerable uncertainties. Programs like PACC have the potential to make important steps toward the development of guidelines, tools and methods for better coping with and adapting to adverse effects of climate change even in areas like the Peruvian Andes.

Acknowledgements. The PACC (Programa de Adaptación al Cambio Climático en el Perú) and the related research is funded by the Swiss Agency for Development and Cooperation, SDC).

Edited by: R. Garraud

Reviewed by: one anonymous referee

\section{References}

Agrawal, A.: Adaptation, Institutions and Livelihoods. Disscusion Paper of the World Bank Discussion Forum on Local Institutions and Adaptation to Climate Change, online available at: http:// www-esd.worldbank.org/ricc/index.cfm?Page=Forums, 2007.

Barnett, T. P., Adam, J. C., and Lettenmaier, D. P.: Potential impacts of a warming climate on water availability in snow-dominated regions, Nature, 438, 303-309, 2005.

Bradley, R. S., Vuille, M., Diaz, H. F, and Vergara, W.: Climate Change: Threats to Water Supplies in the Tropical Andes, Science, 312, 1755-1756, doi:10.1126/science.1128087, 2006.

Dessai, S., Hulme, M., Lempert, R., and Pielke Jr., R.: Do we need better predictions to adapt to a changing climate? EOS Transactions, American Geophyiscal Union, 90(13), 111-112, 2009.

Doran, P. T. and Kendall Zimmerman, M.: Examining the Scientific Consensus on Climate Change, EOS Transaction, 90(3), 22-23, doi:10.1029/2009EO030002, 2009.

Gilles, J. L. and Valdivia, C.: Local Forecast Communication in the Altiplano, B. Am. Meteorol. Soc., 90(1), 85-91, doi:10.1175/2008BAMS2183.1, 2009.
Haylock, M. R., Peterson, T. C. , Alves, L. M., Ambrizzi, T., Anunclacao, Y. M. T., Baez, J., Barros, V. R., Berlato, M. A., Bidegain, M. Coronel, G., Corradi, V., Garcia, V. J., Grimm, A. M., Karoly, D., Marengo, J. A., Marino, M. B., Moncunill, D. F. Nechet, D., Quintana, J., Rebello, E., Rusticucci, M, Ssntos, J. L., Trebejo, I., and Vincent, L. A.: Trends in total and extreme South American rainfall 1960-2000 and links with sea surface temperature, J. Climate, 19, 1490-1512, 2006.

Hewitt, K. (Ed.): Interpretations of Calamity, Boston: Allen \& Unwin INC., 1983.

IPCC: Climate Change 2007: Impacts, Adaptation and Vulnerability, in: Contribution of Working Group II to the Fourth Assessment Report of the Intergovernmental Panel on Climate Change, edited by: Parry, M. L., Canziani, O. F., Palutikof, J. P., van der Linden, P. J., and Hanson, C. E., Cambridge University Press, Cambridge, UK, 976 pp., 2007.

Kaser, G., Juen, I., Georges, C., Gomez, J., and Tamayo, W.: The impact of glaciers on the runoff and the reconstruction of mass balance history from hydrological data in the tropical Cordillera Blanca, Perú, J. Hydrol., 282, 130-144, 2003.

Kaser, G. and Osmaston, H.: Tropical Glaciers, Cambridge University Press, Cambridge, 207 pp., 2002.

Mesinger, F., DiMego, G., Kalnay, E., et al.: North American Regional Reanalysis, B. Am. Meteorol. Soc., 87(3), 343-360, 2006.

Moser, S. and Dilling, L. (Eds.): Creating a Climate for Change: Communicating Climate Change and Facilitating Social Change, Cambridge University Press, 2007.

Salzmann, N., Frei, C., Vidale, P. L., and Hoelzle, M.: The application of Regional Climate Model output for the simulation of high-mountain permafrost scenarios, Global Planet. Change, 56, 188-202, doi:10.1016/j.gloplacha.2006.07.006, 2006.

Su, F., Hong, Y., and Lettemaier, D.: Evaluation of TRMM Multisatellite Precipitation Analysis (TMPA) and Its Utility in Hydrologic Prediction in the La Plata Basin, J. Hydrometeorol., 9, 622-640, doi:10.1175/2007JHM944.1, 2008.

Thompson, L. G, Mosley-Thompson, E., Davis M. E, Lin, P.-N., Henderson, K., and Mashiotta, T. A.: Tropical glacier and ice core evidence of climate change on annual to millennial time scales, Climatic Change, 59, 137-155, 2003.

Vergara, W., Deeb, A. M. Valencia, A. M., Bradley, R. S., Francou, B., Zarzar, A., Grünwaldt, A., and Haeussling, S. M.: Economic Impacts of Rapid Glacier Retreat in the Andes, EOS Transaction, 88(25), p. 261 and p. 264, doi:10.1029/2007EO250001, 2007.

Vincent, L. A., Peterson, T. C., Barros, V. R., Marino, M. B., Rusticucci, M., Carrasco, G., Ramirez, E., Alves, L. M., Ambrizzi, T., Berlato, M. A., Grimm, A. M., Marengo, J. A., Molion, D., Moncunill, D. F., Rebello, E., Anunciacao, Y. M. T., Quintana, J., Santos, J., Baez, J., Coronel, G., Garcia, V. J., Trebejo, I., Haylock, M. R., and Karoly, D.: Observed trends in indices of daily temperature extremes in South America 1960-2000, J. Climate, 18, 5011-5023, 2005.

Vuille, M. and Bradley, R. S.: Mean annual temperature trends and their vertical structure in the tropical Andes, Geophys. Res. Lett., 27, 3885-3888, 2000.

Vuille, M., Bradley, R. S., Werner, M., and Keimig, F.: 20th century climate change in the tropical Andes - observations and model results, Climatic Change, 59(1-2), 75-99, 2003. 